\title{
Mature Care and Nursing in Psychiatry: Notions Regarding Reciprocity in Asymmetric Professional Relationships
}

\author{
Marit Helene Hem • Tove Pettersen
}

Published online: 21 January 2011

(C) The Author(s) 2011. This article is published with open access at Springerlink.com

\begin{abstract}
The idea behind this article is to discuss the importance and to develop the concept of reciprocity in asymmetric professional relationships. As an empirical starting point for an examination of the possible forms of reciprocity between patients and nurses in psychiatry, we chose two qualitative in-depth interviews with two different patients. The manners in which these two patients relate to medical personnel-one is dependent, the other is independent-show that this presents challenges to nurses. The theoretical context is provided by the notion of mature care as it has been developed by feminist-oriented ethics of care, in contrast to the notion of altruistic care. In relation to the concept of mature care, we discuss how nursing can be perceived in demanding relationships with patients in psychiatry. Reciprocity implies that, in principle, the interests of the nurses also matter in a nurse-patient relationship. We show that reciprocity-in practice-is complicated and challenging in a number of different ways. Mature care-with its systematic inclusion of relationships and reciprocity_provides an alternative understanding of what takes place between patients and nurses compared with an altruistic notion of care. As such, mature care can be regarded as an useful paradigm for nurse-patient relationships in psychiatry.
\end{abstract}

Keywords Altruism - Asymmetric professional relationships - Mature care · Nurse-patient relationships · Psychiatric nursing - Qualitative research/interviews . Reciprocity

\footnotetext{
M. H. Hem $(\bowtie)$

Center for Medical Ethics, Faculty of Medicine, University of Oslo, Blindern, P.O. Box 1130, 0318 Oslo, Norway

e-mail: m.h.hem@medisin.uio.no

T. Pettersen

Department of Philosophy, Classics, History of Art and Ideas, Faculty of Humanities, University of Oslo, Blindern, P.O. Box 1020, 0315 Oslo, Norway

e-mail: tove.pettersen@ifikk.uio.no
} 


\section{Introduction and Purpose}

The purpose of this article is to deliberate about care in psychiatric nursing. As a starting point we have chosen two interviews with patients admitted to an acute psychiatric ward. ${ }^{1,2}$ The interviews give voice to the two patients' attitudes towards professional care relationships. One patient does not seem very interested in engaging himself in a relationship with nurses (or others), while the other patient shows a large degree of dependency on other people and possibly a need for contact. The idea behind this approach is to discuss the kind of challenges these two patients-each in their own way-represent to the nurses who are supposed to take care of them. As patients-especially within psychiatric contexts-may have suffered unpleasant experiences under care, it is likely to find a wide variation in attitudes towards professional care among patients [11, 12]. Patients can be a challenge to nurses, for instance if they are rejective [13] or, on the contrary, if their longing for contact is strong and overwhelming, or if they are very dependent on others [5]. As a result, nurses have to cope with a wide range of different reactions from patients. Hence, encountering patients in everyday practice in the wards can be considered a significant challenge to the nurses' professional skills. The theoretical context is provided by the notion of mature care $[8,16,17]$. In relation to the concept of mature care, we discuss how nursing can be perceived in demanding relationships with patients in psychiatry. Reciprocity implies that, in principle, the interests of the nurses also matter in a nurse-patient relationship. In practice, reciprocity is complicated and challenging in a number of different ways. Mature care-with its systematic inclusion of relationships and reciprocity-provides the potential to achieve a realistic understanding of what takes place between patients and nurses.

\section{Mature Care}

The American moral psychologist Carol Gilligan $[8,9]$ has advanced the concept of mature care and this concept has recently been further developed by the Norwegian philosopher Tove Pettersen [16, 17]. One core element of the concept of mature care is reciprocity, not one-sidedness. Mature care is meant to portray care as a relational, not an isolated, activity. The center of attention is the interaction between the carer and the person being cared for. With this understanding of care, dialogue, not monologue, is the aspiration. Furthermore, the notion of mature care involves as

\footnotetext{
1 The cases used in this article were taken from extensive empirical material (especially interview transcripts and to some extent field notes) on acute psychiatry gathered by the first author, Marit Helene Hem $(\mathrm{MHH})$ in connection with her PhD thesis [10]. The examples used in this article are also used in another article by Pettersen and Hem [18].

2 The project was approved by the Regional Committee for Medical Research Ethics and the Privacy Ombudsman for Research. Key research ethics principles such as informed consent, the right to privacy, respect for personal integrity, doing no harm and not exploiting participants were carefully assessed throughout the research process. The participants were provided with both written and verbal information about the project. The persons who were interviewed signed consent forms [6, 10, 21, 22].
} 
much concern for oneself as for others. It implies a balancing of one's own interests and those of others. Considered as a virtue, mature care represents a mean between two extremes where selflessness is the excessive extreme and selfishness the deficient extreme [8, 17, 18].

One of the most important advantages of introducing the concept of mature care to the field of psychiatric nursing is that it highlights reciprocity [10]. The idea of reciprocity constitutes one of the basic differences between the two concepts of care; altruistic care has a tendency towards self-sacrifice or can easily lead to selfsacrifice (http://www.thefreedictionary.com/altruism, http://m-w.com/dictionary/ altruism). Altruism is interpreted in various ways, and altruism appears in many gradations. Especially in Scandinavian literature, it is common to define altruism as putting the interests of others before one's own interests. It is also common to conceive altruism as opposed to egoism [1, 14]. It is, however, important to differentiate here, as altruism does not always lead to self-sacrifice [3]. To ignore one's own needs or interests does not necessarily mean a large sacrifice. It is therefore possible to say that self-sacrifice is not always an ideal within the notion of altruism, but that, due to this concept's focus on the interests of others, it is a possible consequence. Difficulties arise when it is (almost) always the other person who is given first priority [10, 16-20]. Reciprocity implies, among other things, that human interests should be equally considered. In the nurse-patient relationship, this means that also the nurses' interests must be considered. Hence, the importance of the nurses' balancing their own interests against those of the patients is central for mature care [10].

Reciprocity is not identical with sharing equally, or exchanging like for like. In this case, there would be no difference between care and justice. The amount of care provided is dependent on the situation. Sometimes it is appropriate to give some people more attention than others; in fact, sharing equally is sometimes harmful. A mature carer is able to adjust care delivery to the actual situation, which means that he/she has to be sensitive towards the context. In a concrete and situated relationship, care ought not to be unlimited, unreflected or one-sided. Reciprocity concerns the acknowledgement of both parties' interests as equal in principle. The fact that asymmetry between persons exists in a concrete relationship, means that in this particular situation one party is able to give more care than the other [18]. Following the above examination of relevant aspects of the concept of mature care, we continue below by presenting two patients' experiences and views on their relationships with nurses in a psychiatric ward.

\section{Two Patients}

Brian

Brian is 27 years old. In recent years, he has been admitted to psychiatric departments relatively frequently. He has no education except elementary school. He lives on welfare and has a small council flat situated in a depraved area of the city. He uses various drugs and hangs around with a couple of other "endangered" 
youths. At times he can be extremely angry and loud and most of the times he has been committed against his will. On many occasions, he had to be managed with bed-belts. $\mathrm{I}^{3}$ know that the staff is scared of him because of his at times violently and aggressive behavior. He has been admitted for a period of several weeks and they do not want to release him until they can refer him to another institution for long-term treatment. Brian wants to be interviewed because he hopes that the research project might shed light upon how terrible it is to be admitted to a psychiatric ward. When he is hospitalized, he spends most of the time in his roomunder his bed covers and in the dark. This is where he comes from, when he turns up to be interviewed, and this is where he returns to directly after the interview. Below are Brian's own words:

I couldn't disagree more with the kind of treatment I get, and I do not see at all that I need treatment. I completely doubt that ... or to be honest: I think it's just nuts what they are busy with in this place, it doesn't lead to anything. For me, it just leads to depressive thoughts about being locked away ... To be shut away as a patient over a period of time-this is completely intolerable, this is not pleasant at all. It's not that everything has to be so damned nice, just for putting it that way, but it's such a strain. Yes, I think it's straining ... I am in good contact with my feelings about what is happening to me. Actually, I am who I am. So ... I have very strong feelings about that ... that I am who I am. I am 27 years old, and I actually feel quite grown-up now, you know, and I have to manage myself though I am living on welfare and so on. I want to be myself, but they don't let me, not in any respect, because if I try they shut me away ...

\section{Tor}

Tor is about 50 years old. He has been admitted about 20 times in the last 25 years. He suffers from bipolar disorder. He is unemployable. A couple of years ago, he married Lynn who is several years younger. She works full time. They live in a flat in a nice part of the city and I was invited there for the interview. Tor and I know each other from many years ago, when I was his nurse on several occasions when he was admitted. In my opinion, the relationship between Tor and myself is good. He is looking forward to the interview, because he has a story to tell and he wants to contribute as a way of showing his gratitude to me for being his nurse. Here is Tor's story:

When you are admitted as a patient and forcibly medicated ... this makes it even harder. The first time I was admitted I was held to the floor by two doctors and they needed the help of a policeman to hold me down, while they gave me an injection, and at that moment I was convinced that they were going to take my life. This is my worst experience with psychiatry ... What is good with psychiatry, to switch over to that, is that you meet fellow humans. In any case, every now and again. People who are engaged in their jobs and

\footnotetext{
3 Here "I" refers to the interviewer (and field researcher), MHH.
} 
people who are engaged in other people's lives. There are hospital priests, there are doctors in charge, and there are nurses who really are fellow humans. This is the positive thing I can say about ... because what helped me to survive, after I came into contact with psychiatry - that was contact with other humans. That is: the sense of safety or unsafety they provided for me ... They showed me that I can trust them in the long run. Because I have been there several times over quite a period of time. So if it is possible to trust a person over some time, I really begin to trust this person. But not on the first encounter ... I don't give a shit about first impressions. If I'm going to develop a relationship with someone, I must be able to trust this person over time. I've been in contact with quite a few doctors over time and a lot of nurses. You could almost say that some of them have followed me all the way. And you were actually with me, when I experienced some of my worst bouts ... I chose my own life, and since then life has been alternately Heaven and Hell for me, changing from day to day. Up and down, you know ... There is a golden thread in our lives, a thread of life, and your choices today are influenced by your earlier choices. This means that you cannot change direction just deliberately, you simply can't get away from your own past ... I was always very creative when I was admitted ... written many songs and so on. This happened in the maniac phases; and afterwards came the depression, because I began to feel the full impact of being mentally ill, having the low social status those with a mental disease have, and of being unemployable and so on. But I used the money I got on welfare to be creative, and this eventually turned out to be a good solution ... And what Adam (assistant medical director; our comment) said to me the other day, about whether I should take the medicine or not: that even if I tried to deceive my wife to believe that I had taken the medication, I wouldn't manage. But all of a sudden, I realized that she had informed on me and I said this to Adam, and there was a small confrontation. And then Adam said to me "We can't trust you." "I don't trust you either", I said. "The only one I trust is myself." But then the confrontation was over... And then everything was solved in a good way: I will go to the hospital every day during daytime to take my medication. Adam and I are always able to find a solution. Although he used to insist on his opinions and I on mine, we manage to solve the disputes or conflict. And this is probably one of the reasons why I trust him blindly as a professional, and he relies on me. He has faith in what I am doing. And this is just great, because I've got the feeling that I've found a friend for a lifetime, I feel that ...

\section{Analysis}

\section{Independence and Lack of Reciprocity}

Below, we will provide detailed analyses of the stories of Brian and Tor by applying the concept of mature care, especially the notion of reciprocity, as a theoretical lens, supplemented by insights from other relevant literature. The aim is to illustrate the 
different attitudes of the two patients towards the health care system, towards "psychiatry" and receiving care. Brian is younger, but has already been admitted several times. He is extremely skeptical. He is discontent with almost everything he experiences. Brian feels that his needs are not being met or understood. On the contrary, he believes that psychiatry invades his life and creates a lot of unnecessary pain and disorder. He contends that he became depressive because of being locked away. This is why he is convinced that he does not need treatment. He is quite clear about this when he says that this is not an appropriate treatment for him. He expresses very clearly that he is who he is and that he will be who he is. Although life is not especially decent for him—on the contrary: it is kind of a strain-it almost looks as if he has made himself independent. In a way, he has freed himself, uncoupled himself. He does not need anybody, he wants to be on his own and wants to enter and leave relationships with other drug addicts, who otherwise live their own lives, just as it pleases him. In the interview, MHH tried to challenge this position of independence, or the lack of reciprocity in what he said. MHH had, in fact, observed encounters between Brian and staff members that conveyed the impression of personal warmth and contact. However, it is doubtful that MHH got through to Brian when she asked him what it was about these situations. He just referred to the fact that everyone tries to be nice to each other at Christmas time. Our view is that Brian has abandoned the possibility of engaging himself in a relationship. It seems that he has decided that there is nothing more to gain from relationships with others. He has probably had too many bad experiences. He creates a link between his own vulnerability_due to his difficult life-and his criticism of the apparatus of psychiatric power that turned him into an object to be placed wherever it is suitable. Brian —or rather Brian's reclusiveness and his lack of capacity regarding reciprocity-represents a challenge for those nurses who really want to come into contact with him. With a few exceptions, most of these attempts seem to fail.

\section{Dependence and Reciprocity}

Tor's story, on the other hand, appears to have a completely different "relational value." It seems as if his worst experiences of psychiatric care were, in fact, the first experiences he had. Because: what he describes as his first admission, when he was held to the floor, given an injection and convinced they were going to take his life, has been followed by a long period of contact with and dependency on people within the psychiatric health care system (as well as from other areas). It should be pointed out that he mentions many different persons, nurses, doctors and hospital priests. He is aware of the fact that he depends on the help he gets and receives from these people, again and again. He is very clear about the fact that other people make him feel safe or calm, or, on the contrary, unsafe and restless. It appears as if he is extremely occupied with this, and he seems to know at once whether he is safe or not. What is decisive is contact. For Tor, this is a question of trust (over time). He is quite clear about his own role in establishing relationships with others. By this, he acknowledges that he, too, is responsible for what happens around him. We believe that he, in the same way as Brian, talks about sides of himself in a 
matter-of-fact-manner: they are what they are. He talks about his artist's soul, his maniac side, his creative soul. He tells us that this side of him has been both a blessing and a curse, both "Heaven" and "Hell", both up and down. This is the golden thread of his life, his thread of life, and he has taken responsibility for his life by exploiting the potential that lay there. Although his mental disease and living on a disability pension led to having a low social status in society, he identified the opportunity to be creative. He appears to be full of energy and to have a positive disposition, although it can be quite bumpy on the way. Tor understands perfectly well that the doctor gets worried when he, Tor, breaks the agreement they have and does not take his medicine. They have known each other for a long time, and what has broken down in the situation Tor refers to is trust. It is a mutual crisis of trust, and both of them make this clear. But Tor is aware that he has to take responsibility, and he understands that he has to commit himself. He does this first by admitting that he did not take his medicines. Afterwards, he starts to negotiate about how everything should be handled, when he takes up his medication again. When he describes this situation, he actually says that he trusts the doctor blindly. He also takes an active part in the relationship with MHH during the interview. By inviting her to his place and playing music to her, which he himself has composed, he is offering himself to her. He is actively engaged in establishing a relationship between them.

\section{Summing up}

It is interesting that these two interviews differ so much from each other-not only with respect to content, but also to form. The interview with Brian is shorter, but in actual fact, it lasted almost twice as long as the interview with Tor. The interview with Tor lasted $20 \mathrm{~min}$; after that, he ran out of time because he had other chores waiting for him. Nevertheless, he managed to say more than Brian did. This, we believe, reflects some of the differences between them regarding their attitude toward relationships as well as their behavior within relationships. While Brian is withdrawn, lingering and hesitating, Tor is energetic, verbal and associative. To sum up, one could say that Brian appears to be convinced that he does not need relationships that are built on reciprocity, while Tor seems to depend on being in relationships with others.

\section{Discussion: Reciprocity in Asymmetric Professional Relationships}

In the introduction, we pointed out that the perspective of reciprocity-i.e. that the carer in principle is as important as the person receiving care-is central to the concept of mature care [18]. We then went on to focus on interviews with two patients. These two interviews are of special interest because we believe they have great potential for deepening our understanding of how patients' attitudes towards relationships can differ greatly. The interviews challenge a theoretically important issue relating to mature care that all parties' interests are equal. Hence, they show that mature care in practice means to consider the importance of the interests of everybody involved in a situation, included the context in which they appear. 
In the presentation so far, we have let ourselves be guided by one important though not explicitly formulated premise, namely that what we are talking about is professional relationships. Professional care relationships are asymmetric, because there is always one party - the carer or caregiver, in this case the nurse-who is obliged to provide the help another individual - the one who is to receive careneeds. But this does not apply in reverse-it is an unilateral responsibility; the one who is in need of care is in no way responsible for the carer. Therefore, the main concern in this discussion is to make an in-depth study of and problematize the question of how reciprocity in mature care should be understood within the context of asymmetric professional relationships. The fact that the two patients present different challenges to the professional carers, to the nurses, can help illustrate that reciprocity can be understood in different ways.

\section{Endeavors to Establish Contact}

Above, we have shown that Brian and Tor relate to their surroundings in different ways, and that they therefore present different challenges to the nurses. It is quite easy to see Brian's self-centeredness; he makes it clear that he wants to be freed from obliging connections. He does not appear to be so very eager to make contact with other people, neither with nurses. He either withdraws-into the darkness of his room under his bed covers - or he disappears into town, gets stoned and when he returns to the ward, he is often extremely aggressive and quite frequently the staff has to control the situation by use of bed-belts. There are no visible efforts on his side to establish reciprocity. Or perhaps there are some vague indicators of such efforts, at least at times? He is eager to be interviewed by MHH. In fact, he says that this is an important project and that he believes that he can make a contribution. He says during the interview that it is great to sit at the table and drink coffee and smoke while he is talking with her. We mentioned before that MHH had observed encounters between him and staff members that gave her the impression of personal warmth, joyfulness and contact. He talks both with her and with members of the staff about his dreams for the future, about another life and about a safe home. Although he is reclusive and self-centered, there are nevertheless some signs of endeavors-weak though they are-to establish contact with others. We make use of the word "contact", because we believe that the notion of contact has something to do with the essence of the relational [15]. Contact implies that you-in one or another way-are connected to others and that this provides a sense of safety and coherence (ibid.). Until now, this notion has not been mentioned in connection with mature care.

But what about Tor? Is he not reaching out to other people and thus relating to others in a pronounced way? Yes, Tor is extraverted, but he is extraverted in a certain way, that is, from a confined position; although he expresses his selfcenteredness in another way than Brian. He is mainly occupied with himself and with his own needs; he is not really able to see other people. He is not ready for a process that could lead to change. He also insists upon being the person he is-using the poetic concept of "the golden thread in our lives" or "thread of life." Although Tor reaches out to other people and is dependent on what could be called "collusion 
with others", this is not the kind of reciprocity that has been discussed as one of the main aspects of mature care which stresses the importance of self-differentiation. However, there are negotiations going on and work to establish trust-endeavors to establish contact-between him and the members of staff.

\section{Self-Differentiation and Reciprocity: The Responsibility of the Carer}

Our discussion of Brian's and Tor's manners of relating to other people-in one way comparable and at the same time completely different-shows that they both present a challenge to nurses. The concept of mature care can make clear that, in the case of Brian, care means offering him caring surroundings, which implies finding different-and perhaps more indirect-ways of exercising care. The nurse canthrough her creativity and imagination-convey to him that she wants to give him something that does him good. She can uphold the perspective that he also needs thoughtful consideration, safety and goodness, although, most of the time, he gives the impression that he seeks to exclude others. The concept of mature care can also shed light upon the carer or caregiver-in this case the nurse-helping her to uphold the concept of crossing the bridge and meeting the patient in his land or at least trying to, always aware of the necessity to preserve her own integrity. To put it more pointedly, the challenge lies in not losing sight of the possibilities of establishing a connection between an "I" and a "you" [4]—at least some notion of connection. This could be the correct approach for the nurse: to establish careful relational threads between Brian and herself. In the case of Tor, an approach along the lines of mature care would rather focus on the differentiation between an "I" and a "you." The perspective that we-the patient and the nurse-are two, that is, that we are distinct from each other, is of importance in order to help the nurse keep her identity and not succumb to the temptation of joining Tor in all his ideas and projects he has in mind. The nurse-following the lines of mature care-acts as a whole person, authentic and relational in her orientation towards patients [7]. She preserves the perspective of the middle ground-she balances concern for oneself with concern for others $[16,17]$. However, the principal starting point is the self. It is only when the nurse realizes that she is distinct from others that she establishes the base from which she can reach out to another person, the patient [23]. When she has found a safe and integrated position for herself-as mature care describes it - it is perhaps easier for the nurse to discover the patients' efforts to establish contact, although these efforts often take a form that makes them difficult to detect and understandas was the case with both patients we included in this article. The nurse realizes that the ontological contention concerning mutual dependency applies to everybody. We believe this is an important aspect to consider when trying to understand reciprocity in asymmetric professional relationships. The nurse is oriented towards reciprocity in so far as she tries to engage the patient in a relationship. She aims at creating a situation where the relationship between them is of importance for-and in the long run can promote - the patient's personal growth [2]. In other words, the nurse has a way of being, an attitude, a kind of disposition that can provide a possibility for growth for the patient. In this way, she uses her own person within the professional relationship. 
Maturity within the concept of mature care, generally spoken, means that you have gone through a development process. This implies that the mature caregiver has overcome both an all-consuming self-absorption (self-centeredness) and total absorption by others (other-centeredness) [16, 17]. To relate this to nursing, this means that the nurse has developed into a person who has the capacity to take both perspectives at the same time-both contact with herself and contact with the patient. She has developed a way of being (in the world), she has grown into her own person-and it is from this position (that is from being a person with a distinctive identity) that she is able to approach patients. It is only as this person with a distinctive identity that she is able to encounter others [23]. This implies that she is able to see herself as distinct from the others. The "other" - the patient-is a different person. It is her distinctiveness that enables her to understand the patient and to have empathy with him [15]. If she has no awareness of herself as distinct from the other, the patient — or has but a vague sense of who she is herself and who the patient is - she is neither going to be able to encounter the patient nor empathize with him. This understanding is radically different from an understanding in terms of altruistic care, the ideal which might has disregard of one's own needs and concerns in a systematic way in order to be able to help others as a possible consequence. From this perspective, it becomes clear how problematic altruism is as an ideal for nursing. Altruism as an ideal is seldom put into words, but the ideal exists as a silent notion and an unuttered expectation with both patients and nurses [10]. We believe it would be difficult to find a nurse who does not know who she is, i.e. not reflect her own needs and concerns, when meeting a patient. Can it be that Brian has felt invaded by nurses who acted with good intentions, but were not able to clearly differentiate between, on the one hand, themselves and the agendas they have as helpers and, on the other hand, who Brian is and what he is engaged in, his life-project? Can it be that Tor's intensive way of seeking contact makes it challenging for nurses because lack of self-differentiation can in this case lead to rejection of patient's interests?

\section{Summary and Conclusion}

The point of departure for the article has been that the idea of mature care and reciprocity provide an useful theoretical framework for nurses working with psychiatric patients who, in different ways, struggle with their capacity to engage in relationships. We shall sum up this discussion by using the notion of altruistic care as a contrast to mature care in order to shed light on the practical implications of reciprocity and mature care. For nurses who have an altruistic understanding of care, Brian can be a challenge, because the nurse's devotion is often rejected, whereas Tor thankfully accepts the care offered by the nurses, and he seems to make the best of the situation. However, by introducing the concept of mature care and reciprocity as one of its essential features, it becomes possible to shed light upon the challenges Tor presents, namely, that the nurse is in danger of losing herself in the patient's world. Taking an approach from the perspective of mature care, we might see more clearly the potential found in Brian's position of isolation and exclusion. Through 
the nurse being relationally oriented-within the context of asymmetric professional relations-she shows a kind of reciprocity which, in the long run, can create a situation for the patient, where the relational dimension helps him to see himself through seeing the other and by being seen by the other. It is precisely in this area where we can find potential for the patient's personal growth-through the relationship with the nurse [2].

In this article, we have only implicitly referred to reflection as an essential dimension of being a mature carer. The same refers to empathy: we have mentioned empathy, but have not explicitly discussed it in detail. Reflection and empathy are decisive in professional care. Empathy and reflection are necessary for contact and connection [15]. To (even more) systematically incorporate empathy and reflection (as important relational dimensions) into mature care could reinforce the concept as a new paradigm for asymmetric professional nursing relationships.

Acknowledgments We would like to express our gratitude to the two patients who were willing to be interviewed. We also thank the hospital administration for permitting us to carry out our study, and the nurses and the rest of the staff who allowed us to observe them and the patients who accepted our presence. The Ethics Programme at the University of Oslo allocated research funds, and Peter Schröder helped us with the language.

Open Access This article is distributed under the terms of the Creative Commons Attribution Noncommercial License which permits any noncommercial use, distribution, and reproduction in any medium, provided the original author(s) and source are credited.

\section{References}

1. Alvsvåg, H. (2006). Kari Martinsen. Philosophy of caring. In A. Marriner-Torney \& M. R. Alligood (Eds.), Nursing theorists and their work (6th ed., pp. 167-190). St. Louis: Elsevier Mosby.

2. Barbera, M. R. (2005). Contemporary psychoanalytic relational theories and imago. In H. Hendrix, H. L. Hunt, M. T. Hannah, \& W. Luquet (Eds.), Imago relationship theory. Perspectives on theory (pp. 122-136). San Francisco: Jossey-Bass.

3. Blum, L. (1980). Friendship, altruism and morality. London: Routledge and Kegan Paul.

4. Buber, M. (1992). Jeg og du. (I and Thou). Oslo: J. W. Cappelens Forlag A.S.

5. Cullberg, J. (2006). Psychoses. An integrative perspective. London, New York: Routledge.

6. Declaration of helsinki: Ethical principles for medical research involving human subjects (2008). World Medical Association. Retrieved 24 Nov 2010 from: http://www.wma.net/en/30publications/ 10policies/b3/17c.pdf.

7. Ekeberg, V. (2001). Utspilt av rollen?-en studie i det moralske menneskets eksistens med utgangspunkt i Sartres tidlige filosofi. (outsmarted by the role? A study of the moral human being's existence based on the early philosophy of sartre). Master thesis. Oslo: University of Oslo.

8. Gilligan, C. (1982). In a different voice. Psychological theory and women's development. Cambridge, London: Harvard University Press.

9. Gilligan, C. (1993). Reply to critics. In M. J. Larrabee (Ed.), An ethic of care: Feminist and interdisciplinary perspectives (pp. 207-214). New York: Routledge.

10. Hem, M. H. (2008). Mature care? An empirical study of interaction between psychotic patients and psychiatric nursing. Doctoral thesis. Oslo: Unipub. http://www.duo.uio.no/publ/sykepleie/2008/ 70654/608_Hem_17x24.pdf.

11. Hem, M. H., Nortvedt, P., \& Heggen, K. (2008). Only a manic depressive! The zone of the untouchable and exceeding limits in acute psychiatric care. Research and Theory for Nursing Practice, 22(1), 56-77. 
12. Hem, M. H., Heggen, K., \& Ruyter, K. W. (2008). Creating trust in an acute psychiatric care. Nursing Ethics, 15(6), 777-788.

13. Lorem, G.F. (2005). Withdrawal and exclusion. A study of the spoken word as means of understanding schizophrenic patients. In Martinsen, K. (2006) Care and vulnerability. Doctoral thesis. Tromsø: University of Tromsø. Oslo: Akribe.

14. Martinsen, K. (2006). Care and vulnerability. Oslo: Akribe.

15. Mason, R. C. (2005). Imago, relationships and empathy. In H. Hendrix, H. L. Hunt, M. T. Hannah, \& W. Luquet (Eds.), Imago relationship theory. Perspectives on theory (pp. 139-161). San Francisco: Jossey-Bass.

16. Pettersen, T. (2004). Comprehending care. Problems and possibilities in Carol Gilligan's ethics of care. Doctoral thesis. Oslo: Unipub.

17. Pettersen, T. (2008). Comprehending care. Problems and possibilities in the ethics of care. Lanham, Boulder, New York, Toronto, Plymouth UK: Lexington Books. http://www.lexingtonbooks.com/ Catalog/SingleBook.shtml?command=search\&db=\%5EDB/CATALOG.db\&eqSKUdata=0739126156.

18. Pettersen, T., \& Hem, M. H. (2011). Mature care and reciprocity: Two cases from acute psychiatry. Nursing Ethics (in press).

19. The Free Dictionary. Retrieved 21 Nov 2010 from: http://www.thefreedictionary.com/altruism.

20. Meriam-Webster Online Dictionary. Retrieved 21 Nov 2010 from: http://m-w.com/dictionary/ altruism.

21. Roberts, L. W. (1998). The ethical basis of psychiatric research: Conceptual issues and empirical findings. Comprehensive Psychiatry, 39(3), 99-110.

22. Roberts, L. W., \& Roberts, B. (1999). Psychiatric research ethics: An overview of evolving guidelines and current ethical dilemmas in the study of mental illness. Biological Psychiatry, 46, 1025-1038.

23. Vatne, S. (2006). Korrigere og anerkjenne. Relasjonens betydning i miljøterapi. (The importance of relations in milieu therapy). Oslo: Gyldendal Akademisk. 